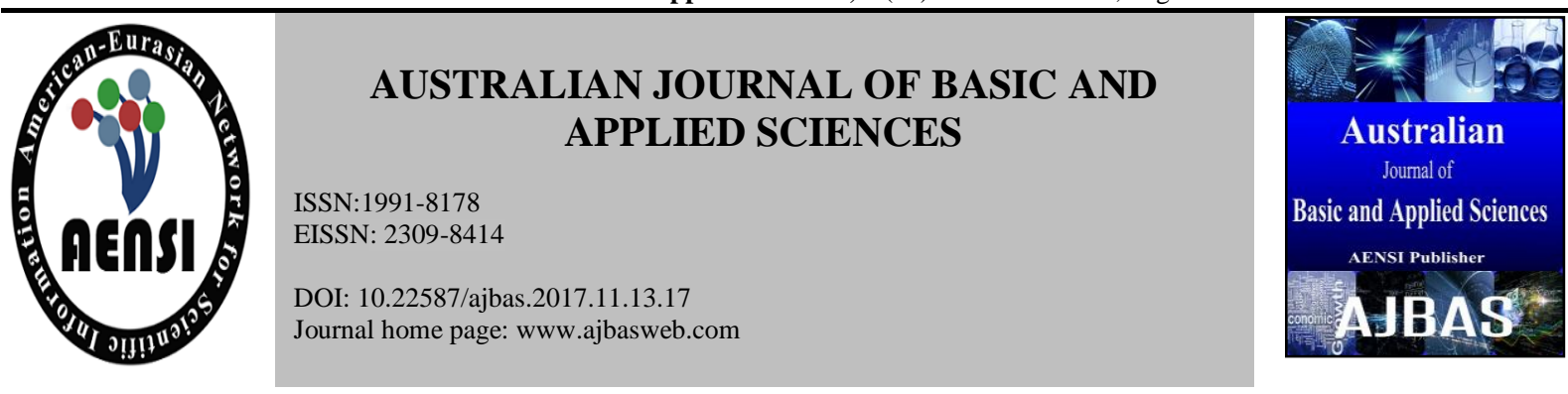

\title{
Hepatitis B knowledge among male School teachers at Al-Iskan sector in Makkah Al Mukarramah 2011
}

Khalid ShaafAlmalki ${ }^{1}$, Khalid Abdullah Almasaodi ${ }^{1}$, Khalid Abdullah M Almatrafi ${ }^{2}$, Saif Mutair Alhuzali ${ }^{1}$, Nawaf Ateeq Alfadli ${ }^{3}$, Essam Muawadh Alrihaili ${ }^{3}$, Rayan Abdulrahman Alsaidi ${ }^{2}$

${ }^{1}$ Consultant of Family Medicine, KSA

${ }^{2}$ Family Medicine resident, $K S A$

${ }^{3}$ Health Management Specialist, KSA

Address For Correspondence:

Khalid Shaaf Almalki Consultant of Family Medicine, KSA

E-mail: dr.khalidphc@gmail.com

\section{A R T I CLE INFO}

\section{Article history:}

Received 12 October 2017

Accepted 10 November 2017

Available online 14 December 2017

Keywords:

Hepatitis B, Knowledge, HbsAg carrier

\begin{abstract}
A B S T RA C T
Background: Saudi Arabia is considered to be an area of endemic hepatitis B virus (HBV) infection. Among Saudi children, the overall HbsAg carrier rate dropped from $6.7 \%$ in 1989 to $0.3 \%$ in 1997 after mass $\mathrm{HB}$ vaccination program among adults prevalence is $0.22 \%$. The prevalence varied by region, ranging from $0.03 \%$ to $0.72 \%$ with a mean incidence of $0.15 \%$. Objectives: To determine level of knowledge about hepatitis B and its associated factors among school teachers at Al-Iskan sector in Makkah Al Mukarramah. Subjects and methods: A Cross-sectional community-based study was adopted. It included all-male school teachers in primary, intermediate and secondary stages at Al-Iskan sector in Makkah Al Mukarramah. A self-administered valid questionnaire was utilized for data collection. It included personal data, questions regarding etiology, epidemiology, symptomatology, risk factors, preventive measures and outcome of hepatitis B. Results: The research involved 137 medical students. Their age ranges among 21 and 28 years with an average of 23.0 and $( \pm$ SD) of $( \pm 0.9)$ years. Slightly more than half of them $(50.4 \%)$ were males. All students ever used Facebook and used it in the last year. Almost two-thirds of students $(62.7 \%)$ checked their Facebook account daily whereas $5.1 \%$ checked it within a one-hour interval. Overall, based on the BFAS cut-off level, Facebook addiction was identified among 13 students representing $9.5 \%$ of the participants. Addiction was more reported among older students, $\mathrm{p}=0.038$ and those who spent between 21 and $40 \%$ of their Facebook time on work-related issues, $\mathrm{p}=0.034$. Conclusion: inadequacy of knowledge regarding HBV among teachers in Al-Iskan sector, Makkah in certain key areas of HBV. This lack of knowledge is a matter of concern since teachers could disseminate their information to young youth at schools.
\end{abstract}

\section{INTRODUCTION}

More than two thousand million people have been infected with Hepatitis B virus elsewhere. Of these, about 350 million remain infected chronically and become carriers of the virus. ${ }^{(1)}$ Of whom approximately $75 \%$ are Asian(Key, 2003).Hepatitis B is endemic in China, and other parts of Asia, $8 \%$ to $10 \%$ of the adult population are chronically infected(World Health Organization, 2000). In the Middle East and Indian subcontinent, an evaluated $2 \%$ to $5 \%$ of the public people are a chronic disease(World Health Organization, 2000; Key, 2003). Less than $1 \%$ of the people in Europe and the American continent is a chronic disease(Leung et al., 2010).

\footnotetext{
Open Access Journal

Published BY AENSI Publication
}

(C) 2017 AENSI Publisher All rights reserved

This work is licensed under the Creative Commons Attribution International License (CC BY).http://creativecommons.org/licenses/by/4.0/

\section{C) (†) Open Access}

To Cite This Article: Khalid Shaaf Almalki, Khalid Abdullah Almasaodi, Khalid Abdullah M Almatrafi, Saif Mutair Alhuzali, Nawaf Ateeq Alfadli, Essam Muawadh Alrihaili. Hepatitis B knowledge among male School teachers at Al-Iskan sector in Makkah Al Mukarramah 2011.Aust. J. Basic \& Appl. Sci.,11(13): 146-152, 2017 
A study was done to known Saudi dental patients' knowledge of hepatitis B virus (HBV) and hepatitis $\mathrm{C}$ virus (HCV) infections and its information of transmission as well as to than the HBV and HCV information and the actual application of men and women.

The study concludes that usually could be made to improve and perform hepatitis B and C cultural awareness for Saudi society. These usually may be appropriate for the male and female public(al-Faleh et al., 1992). The objective of public-wide knowledge-raising by campaigns and health care worker teaching is wanted to become better informed of HBV and HCV (Ashri, 2008).

This study aimed to determine the levels of knowledge regarding hepatitis B among male School teachers at Al-Iskan sector in Makkah Almukarramah.

\section{PATIENTS AND METHODS}

This study was a cross-sectional study carried out in Makkah city included 224candidates. This study included male school teachers in primary, intermediate and secondary stages at Al-Iskan sector in Makkah Al Mukarramah.

\section{Ethical Approval}

This study was approved from the regional research center and director of primary health care in Makkah. Each participant gave verbal consent prior to recruitment and confidentiality was assured for each situation.

\section{Study sample size calculation and method of sampling}

The minimum number was 236individual. The calculation of the sample size was done by using Raosoft sample size calculator with assuming of $95 \%$ confidence level, 5\% sampling error, and 50\% probability of prevalence. The study included all male teachers of all educational stages (primary, intermediate and secondary). The total number of teachers in the eight schools in Al-Iskan sector is236teachers. Invitations have been sent to them and only $224(94.9 \%)$ teacher responded. Data were collected through a self-administered questionnaire.

Validity and reliability of the questionnaire were tested by two family medicine consultants. The questionnaire was distributed to each participant's hand to hand by the researcher for the assurance of confidentiality. The questionnaire included personal data, questions regarding etiology, epidemiology, symptomatology, risk factors, preventive measures and outcome of hepatitis B.

\section{Pilot study}

A pilot study was conducted on 50 teachers in one school (not included in the final analysis). The purpose was to estimate the time needed for data collection and the questionnaire, as well as the methodology, were tested and necessary modifications were done accordingly.

\section{Data analysis}

Collected data were verified and coded before computerized data entry. The researcher utilized the Statistical Package for Social Sciences (SPSS version 19.0) for data entry and analysis. Percentages, mean and SD were used as descriptive statistics. Teachers' knowledge score regarding hepatitis B was calculated as follow; the participated teachers were asked to answer questions about the etiology, mode of transmission, susceptible victims, common symptoms, preventive measures, treatment and outcome of hepatitis B. Right answer is giving the highest score. The overall score was calculated in the way that the higher the score, the higher the knowledge regarding ARTIs (the score ranged between 0-30).

Bivariate analyses of mean scores with regard to independent variables were done by ANOVA. Least significance difference test (LSD) test was used for post hoc comparisons of ANOVA.A p-value of less than 0.05 will be adopted for statistical significance. The median level of the total knowledge score was utilized as cut-off level. Teachers with a total knowledge score equal or above the median value (17) were considered having good knowledge while those whose score was lower than the median value were considered as having bad knowledge. Multiple associations were evaluated in multiple logistic regression model based on the backward stepwise selection, where significant variables from the bivariate analysis were included. This procedure allowed the estimation of the strength of the association between each independent variable while taking into account the potential confounding effects of the other independent variables. The covariates were removed from the model if the likelihood ratio statistic based on the maximum likelihood estimates had a probability of $>0.10$. Each category of the predictor variables was contrasted with the initial category (reference category). The adjusted measure of association between risk factors and teachers` knowledge was expressed as the odds ratio (OR) with 95\% Confidence Interval (95\% CI). Adjusted or crude ORs with 95\% CI that did not include 1.0 were considered significant. 


\section{Demographics}

The research involved 224 teachers, their age, which ranged among 22 and 59 years with an average of $38.91 \pm 7.18$ years. From Table (1) it could be noticed that little more than fifty percent of the teachers; 118 $(52.7 \%)$ aged among 36 and 45 years and 38 (17\%) were over 45 years. Most of them were Saudi (83.9\%). Slightly more than half of them $117(52.2 \%)$ were teaching secondary stage. It was found that the majority 206 $(92 \%)$ were university graduated. Almost one quarter; 51 (22.8\%) were specialized in Arabic and 11 (4.9\%) were administrators.

\begin{tabular}{|l|c|c|}
\hline \multicolumn{2}{|c|}{ Table 1:- Demographic characteristics of the study group } \\
\hline \hline Characteristics & No. & $\%$ \\
\hline \hline Age in years & & \\
$\leq 35$ & 68 & 30.4 \\
$36-45$ & 118 & 52.7 \\
$>45$ & 38 & 17.0 \\
\hline Nationality & & \\
Saudi & 188 & 83.9 \\
Non Saudi & 36 & 16.1 \\
\hline Qualification & & \\
University & 206 & 92.0 \\
Diploma & 16 & 7.1 \\
Master & 2 & 0.9 \\
\hline Specialty & & \\
Physical education & 11 & 4.9 \\
Arabic & 51 & 22.8 \\
Religious studies & 32 & 14.3 \\
Social studies & 18 & 8.0 \\
Science & 43 & 19.2 \\
English & 13 & 5.8 \\
Mathematics & 24 & 10.7 \\
Administrators & 11 & 4.9 \\
Others & 21 & 9.4 \\
\hline Educational stage & 64 & 28.6 \\
Primary & 43 & 19.2 \\
Intermediate & 117 & 52.2 \\
Secondary & & \\
\hline \hline
\end{tabular}

\section{Awareness of Disease}

The majority of the participants $(193 ; 86.2 \%)$, we're aware of hepatitis B infection as shown in figure (1). Among those who claimed that they have information about hepatitis B, $73.6 \%$ had their information from media while $40 \%$ and $27.5 \%$ had their information from hospital/medical center and internet respectively. The majority of teachers $(202 ; 90.2 \%)$ considered community knowledge about hepatitis B not enough and there is a need for community health education regarding hepatitis B infection.

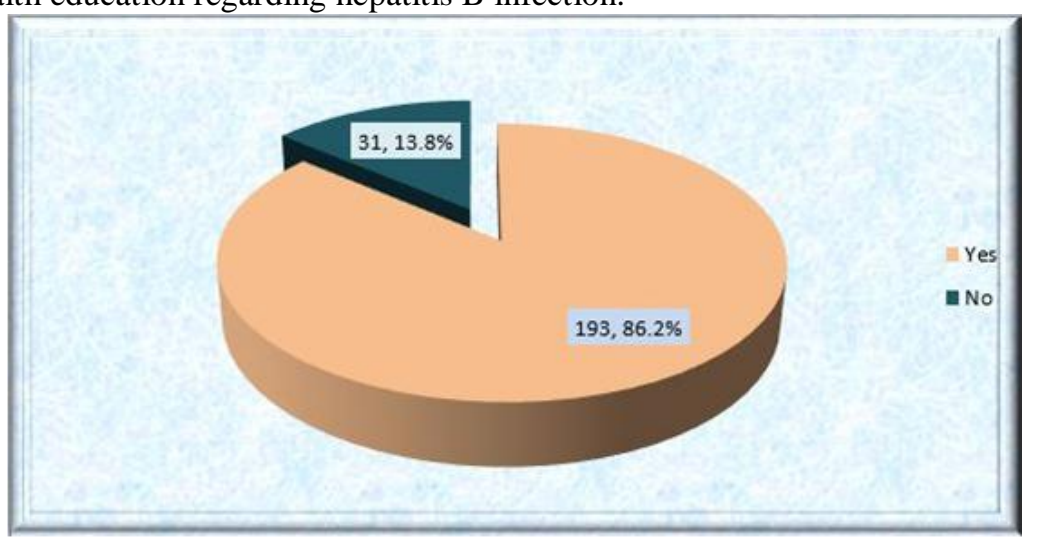

Figure 1: Self-reporting of the teachers 'awareness of hepatitis B infection. 


\section{Assessment of knowledge}

Etiology

The majority of teachers $(195 ; 87.1 \%)$ recognized that hepatitis B is a viral disease while only 83 teachers $(37.1 \%$ ) recognized that the prevalence rate of hepatitis B carriers in Saudi Arabia lies between $8 \%$ and $15 \%$.

\section{Symptomatology}

As shown in table (2), jaundice was the most correctly recognized symptoms of hepatitis B (58.5\%). Loss of appetite, general weakness, nausea, and vomiting were recognized as symptoms of hepatitis B by $36.2 \%$ of participants, while upper abdominal pain recognized as hepatitis B symptoms by only $21 \%$ of teachers.

\begin{tabular}{|l|l|l|}
\hline Table 2: Assessment of knowledge of disease symptomatology among teachers. \\
\hline Symptoms & \multicolumn{2}{|l|}{ Right answer } \\
\cline { 2 - 3 } & \multicolumn{1}{|l|}{ No. } & $\%$ \\
\hline \hline & & \\
Jaundice (true) & 131 & 58.5 \\
Loss of appetite, general weakness, nausea and vomiting (True) & 81 & 36.2 \\
Upper abdominal pain (True) & 47 & 21.0 \\
Intestinal obstruction (False) & 207 & 92.4 \\
ALL (Jaundice + Loss of appetite +upper abdominal pain) & 9 & 4.0 \\
Do not know & 12 & 5.4 \\
\hline \hline
\end{tabular}

\section{Spread of infection}

Most of the participated teachers $(173 ; 77.2 \%)$ recognized that there are more susceptible groups to get infected with hepatitis B virus than others and that the spread of hepatitis B infection in the community is preventable (168; 75.5\%). Regarding prevalence of hepatitis B infection in the community, slightly less than half of the participants $(105 ; 46.9)$ have mentioned that blood transfusion is responsible for that while more than half of teachers $(136 ; 60.7 \%)$ have reported that lack of community health awareness about hepatitis B prevention is responsible for high prevalence of hepatitis B in the community. As obvious from figure (2), almost two-thirds of teachers (67.4) have reported only one reason while only 4 teachers (1.8\%) have reported all the five reasons for the high prevalence of hepatitis B in the community.

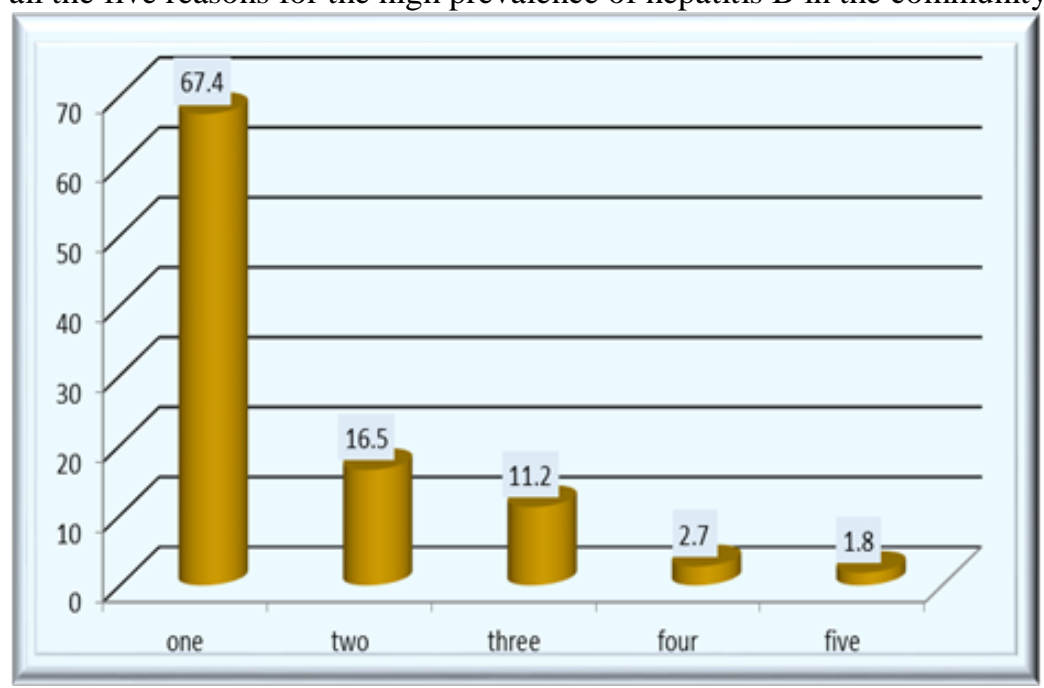

Figure 2: Teachers` knowledge of the reasons for hepatitis B community spread (number of reasons).

\section{Transmission patterns}

The majority of participated teachers $(211 ; 94.2 \%)$ recognized that using an infected needle is a method of hepatitis B transmission. Blood and organ transportation from infected person was recognized as a method of hepatitis B transmission by 191 teachers $(85.4 \%)$. On the other hand, the majority of teachers $(90.2 \%)$ recognized that shaking hands of infected patients is not a way of hepatitis B transmission.

\section{Preventive measures}


Almost two-thirds of teachers have reported that hepatitis B infection spreads slowly between family members and most of them $(83.9 \%)$ have recognized that hepatitis B infection could be controlled effectively within family. Approximately two-thirds of teachers (64.7\%) reported that no application of sterilization precautions in barbershops is a method for spread of hepatitis B infection while less than half of them reported that non application of sterilization precautions in dentist clinics (42\%) and Hegama places (47.3\%) are methods for spread of hepatitis B infection. Fortunately, most of teachers (82.6\%) knew that non application of sterilization measures in restaurants and kitchen is not a method for transmission of hepatitis B. Most of teachers are aware of the preventive measures within family, $84.8 \%$ reported that avoiding use of sharp instruments, tooth brush or glucometer of others is the main preventive measure while on the other hand, most of teachers recognized that isolation of infected person and avoid eating with him were not protective measures against hepatitis B transmission. More than two-thirds of teachers recognized that there is a vaccine against hepatitis B (69.2\%). Approximately $61.6 \%$ and $37.9 \%$ of teachers realized that vaccine is given at birth and given in three doses respectively.

\section{Outcome}

The majority of teachers $(93.8 \%)$ recognized that hepatic cirrhosis is an outcome of hepatitis B infection, while $71.9 \%$ reported that liver cell carcinoma is an outcome of hepatitis B.

\section{Treatment of $\mathrm{HBV}$}

More than half of the teachers $(118 ; 52.7 \%)$ reported that there is a drug that could accelerate the hepatitis B cure.

\section{Teachers' Attitude toward HBV infection}

More than one-third of participated teachers (37.5\%) either did not know or were not sure where they should go when they get infected with hepatitis B in order to seek advice. Besides, almost one-third of teachers participated in the study $(31.7 \%)$ have reported that if they got infected or a family member or a friend, there is a site $\mathrm{s}$ advised them.

\section{Factors affecting knowledge}

Teachers with master's degree had a significant higher knowledge score than those with university or diploma degrees and teachers with university degree had knowledge about hepatitis B significantly higher than those with diploma degree. In conclusion, teachers` qualification is significantly associated with hepatitis B knowledge level. Hepatitis B knowledge among teachers was highest among those taught intermediate stage and lowest among those taught primary stage. This difference was statistically significant $(\mathrm{p}<0.001)$. Other factors like age, nationality and specialty were found to be non-significant.

\begin{tabular}{|c|c|c|c|}
\hline & Mean & SD & P value \\
\hline \multicolumn{4}{|l|}{ Age in years } \\
\hline$\leq 35(68)$ & 16.90 & 4.20 & \multirow{3}{*}{0.853} \\
\hline $36-45(118)$ & 16.88 & 2.82 & \\
\hline$>45(38)$ & 16.55 & 3.05 & \\
\hline \multicolumn{4}{|l|}{ Nationality } \\
\hline Saudi (188) & 16.76 & 3.46 & \multirow{2}{*}{0.474} \\
\hline Non Saudi (36) & 17.19 & 2.47 & \\
\hline \multicolumn{4}{|l|}{ Qualification } \\
\hline University (206) & 16.99 & 2.30 & \multirow{3}{*}{0.008} \\
\hline Diploma (16) & 14.50 & 2.83 & \\
\hline Master (2) & 19.50 & 0.71 & \\
\hline \multicolumn{4}{|l|}{ Specialty } \\
\hline Physical education (11) & 17.55 & 2.77 & \multirow{10}{*}{0.082} \\
\hline Arabic (51) & 17.04 & 2.89 & \\
\hline English (13) & 16.85 & 3.16 & \\
\hline Science (43) & 17.86 & 2.97 & \\
\hline Social studies (18) & 14.94 & 4.76 & \\
\hline Islamic studies (32) & 16.47 & 3.82 & \\
\hline Mathematics (24) & 17.17 & 3.55 & \\
\hline Administrators (11) & 16.73 & 1.79 & \\
\hline Others $(21)$ & 15.67 & 2.87 & \\
\hline & 16.83 & 3.32 & \\
\hline \multicolumn{4}{|l|}{ Education stage } \\
\hline Primary (64) & 15.45 & 3.63 & \\
\hline
\end{tabular}


Australian Journal of Basic and Applied Sciences, 11(13) November 2017, Pages: 146-152

\begin{tabular}{|l|l|l|l|}
\hline Intermediate (43) & 18.02 & 3.11 & $<0.001$ \\
\hline Secondary (117) & 17.15 & 2.98 & \\
\hline
\end{tabular}

Determinants for teachers`knowledge about hepatitis $B$ infection

In the multivariate analysis, teachers taught intermediate stage had three folded better knowledge than those taught primary stage $(\mathrm{OR}=2.97 ; 95 \% \mathrm{CI}=1.29-6.29)$ while teachers taught secondary stage had almost double fold of better knowledge as compared to those taught primary stage ( $\mathrm{OR}=1.92 ; 95 \% \mathrm{CI}=1.05-7.35)$. However, teachers`qualification was not associated with his knowledge level.

\section{DISCUSSION}

The research involved 224 teachers with a response average of $94.9 \%$. This great response average can perhaps be attributed to the personal contact of researcher with the schools' managers in addition to the illustration of the objective of the research, scientific significance and worth of the study to every teacher. Rosnow and Rosenthal, (1999)who found that these techniques (e.g. personal link, utilizing reminders and illustrate the scientific significance and value of the research, including the involvements' particularity) are connected to greater involvement in surveys.

HBV infection is maybe due to by DNA virus with incubation duration of 21-135 days(Arnold S, 1991). HBV infection kills approximately 1.1 million populations globally each year(Key, 2003). Moreover, the happening of HBV infection may is be decreasing by confirming proper education regarding its transmission and universal immunization of infants with hepatitis B vaccine.

Our research, approximately one-third of the teachers were aware of the prevalence rate of hepatitis B carrier in KSA and two-thirds were aware of the existence of hepatitis B vaccine(El Beltagy et al., 2008). In a study carried in India among pregnant married women in the reproductive age(Sharma, Sharma and Khajuria, 2004), about $20 \%$ of the female was having knowledge of the method of transmission of HBV and practicing protective measures such as sterile needles. Fifty percent of the females were having a misunderstanding concerning the method of transmission of HBV infection such as fecal-oral route, physical contact, and others. In the current study, Saudi teachers had sufficient knowledge regarding some risk factors such as blood transfusion, needle stick injuries and transplacent spread from infected mothers while they had poor knowledge regarding sexual transmission as well they had misconceptions like the possibility of transmission of hepatitis B virus through lactating mother to her baby.

In the present research, teachers' information appears to be unqualified and not enough for connecting influential protection practices versus viral hepatitis (particularly sexual protection and role of vaccination). Interviewees' self-acknowledgment of the requirement for knowledge was apparent pointing to the requirement for development in actions to published suitable information on viral hepatitis and participation with schools to prepare teachers to elevate the protection of HBV.

In the present research, the media was showed to be the main source of knowledge. Therefore it is greatly recommendable to use this source of knowledge to published education concerning the protection of the HBV infection.

The teachers` knowledge in the present study was shown to be inadequate in relation to transmission (particularly sexual) and to prevention (sexual, improper patients` isolation and avoid eating with infected patients). In this category, it was found that based on these findings; there is high worry around utilize of utensils, like dishes, and glasses utilized by diseased people. The belief that utilize utensils polluted by infected persons, particularly those that come into connection with the mouth, is greatly spread in our society. This could be a popular origin in the impregnation of the common imaginary with the knowledge that some diseases, such as h1n1 flu, can be transmitted in this method. Another participate agent may be the generalization, in the media, of the wrong explaining of study outcomes around pollution with fecal coliforms of restaurant utensils, which generally finding from utilizing of population water and not from start handled by diseased persons.

In the current study, $42 \%$ and $64.7 \%$ of teachers reported that lack of sterilization precaution in dental clinics and barbershops respectively were risk factors for acquiring hepatitis B viral infection. Comparable figures have been reported in another study conducted in India(Khandait, Ambadekar and Vasudeo, 1999).

Hepatitis B viral infection which eventually causes liver cirrhosis and liver cancer is fortunately preventable by vaccination (Pungpapong, Kim and Poterucha, 2007). The majority of teachers in the present study $(93.8 \%)$ knew that hepatitis B infection leads to liver cirrhosis while only $(71.9 \%)$ knew that it leads to liver cancer. A lower percentage has been reported in another study conducted Taiwan(Chang et al., 1997).Immunization with hepatitis B vaccine plays a very important role in controlling occurrence of HBV infection(MMWR, 1990).In the current study, $69.2 \%$ of the teachers recognized the existence of hepatitis B vaccine. In general, the information regarding hepatitis B vaccination was quite acceptable except for the number of doses.

Although the contradiction among knowledge connection the modes of transmission and recommendations on protection has been shown on some occasions (Gaze, de Carvalho and Rangel-Tura, 1997; 
Gaze, Carvalho and Tura, 2006). In the current study, the majority of teachers reported blood born transmission and recommended not using sharp instruments of others to control spread of hepatitis B viral infection.

While this study provided additional information to the field of education in the area of teacher knowledge of HBV, the largest limitations of this study conducted in an inadequacy of knowledge regarding HBV among teachers in Al-Iskan sector, Makkah in certain key areas of HBV was observed. This lack of knowledge is a matter of concern since teachers could disseminate their information to young youth at schools. While observance the volume of the problem it is significant to focus on teachers and inform them concerning the volume of the problem and its protection.

\section{Acknowledgment}

Before all and foremost I must thank Allah, the great almighty, the most merciful for giving me the patience and capability to complete this study. I would express my sincere gratitude to all those who helped, support and advice me during this study.

There is no conflict of interest.

\section{Conflict of interest}

\section{REFERENCES}

al-Faleh, F. Z. et al. (1992) 'Seroepidemiology of hepatitis B virus infection in Saudi Arabian children: a baseline survey for mass vaccination against hepatitis B.', The Journal of infection, 24(2), pp. 197-206. Available at: http://www.ncbi.nlm.nih.gov/pubmed/1533236.

Arnold S, R. J. (1991) 'Hepatitis B', in WE, H. et al. (eds) Current Diagnosis \& Treatment: Pediatrics. 11th edn. New Delhi: accessMedicine.

Ashri, N. Y. (2008) 'Hepatitis B and C knowledge among Saudi dental patients.', Saudi medical journal, 29(12), pp. 1785-90. Available at: http://www.ncbi.nlm.nih.gov/pubmed/19082234.

El Beltagy, K. E. et al. (2008) 'Prevalence of hepatitis B virus markers among blood donors in a tertiary hospital in Tabuk, northwestern Saudi Arabia.', International journal of infectious diseases : IJID : official publication of the International Society for Infectious Diseases, 12(5), pp. 495-9. doi: 10.1016/j.ijid.2008.01.010.

Chang, M. H. et al. (1997) 'Universal hepatitis B vaccination in Taiwan and the incidence of hepatocellular carcinoma in children. Taiwan Childhood Hepatoma Study Group.', The New England journal of medicine, 336(26), pp. 1855-9. doi: 10.1056/NEJM199706263362602.

Gaze, R., de Carvalho, D. M. and Rangel-Tura, L. F. (1997) 'Information from teachers on viral hepatitis transmission and prevention in Brazil.', Salud publica de Mexico, 45(4), pp. 245-51. Available at: http://www.ncbi.nlm.nih.gov/pubmed/12974041.

Gaze, R., Carvalho, D. M. de and Tura, L. F. R. (2006) 'Informação de profissionais de saúde sobre transmissão transfusional de hepatites virais', Revista de Saúde Pública, 40(5), pp. 859-864. doi: 10.1590/S003489102006005000004.

Key, R. S. (2003) 'Vaccine preventable diseases.', in Chaturvedi S, J. T. eds. (ed.) Epidemiology in maternal and child health, Preventive medicine. New Delhi, pp. 40-66.

Khandait, D. W., Ambadekar, N. N. and Vasudeo, N. D. (1999) 'Knowledge and practices about HIV transmission among barbers of Nagpur City.', Indian journal of medical sciences, 53(4), pp. 167-71. Available at: http://www.ncbi.nlm.nih.gov/pubmed/10695229.

Leung, C. M. et al. (2010) 'Public awareness of hepatitis B infection: a population-based telephone survey in Hong Kong.', Hong Kong medical journal = Xianggang yi xue za zhi, 16(6), pp. 463-9. Available at: http://www.ncbi.nlm.nih.gov/pubmed/21135423.

MMWR (1990) Protection Against Viral Hepatitis Recommendations of the Immunization Practices Advisory Committee (ACIP).

Pungpapong, S., Kim, W. R. and Poterucha, J. J. (2007) 'Natural history of hepatitis B virus infection: an update for clinicians.', Mayo Clinic proceedings, 82(8), pp. 967-75. doi: 10.4065/82.8.967.

Rosnow, R. L. and Rosenthal, R. (1999) 'Psychology; Social sciences; Research; Methodology', in Beginning Behavioral Research: A Conceptual Primer. 3rd edn. (Upper Saddle River, NJ): Prentice Hall, pp. 475-81.

Sharma, R., Sharma, C. L. and Khajuria, R. (2004) 'The Knowledge, Attitude and Practices regarding HBV Infection of Married Women in the Reproductive Age Group living in Cantonment Area, Sunjawan, Jammu', Medicine Today. JK sciences, 6(3), pp. 127-30. doi: 10.3329/medtoday.v22i1.5602.

World Health Organization (2000). Available at: www.who.int/en/. 